\title{
"What ELSE about this job?" Teaching Job Decision-Making to College Students With Intellectual and Developmental Disabilities
}

\author{
Ayse Torres $^{1} \oplus \cdot$ Kelly B. Kearney ${ }^{1} \cdot$ Lauren Berlingo $^{1} \cdot$ Michael P. Brady $^{1}$
}

Accepted: 24 September 2021 / Published online: 28 October 2021

(C) The Author(s), under exclusive licence to Springer Science+Business Media, LLC, part of Springer Nature 2021

\begin{abstract}
Decision-making is the central element of self-determination, requiring targeted, systematic instruction to learn. In this study, researchers developed a multicomponent intervention, "What ELSE about this job?", to teach job decision-making skills to college students with intellectual and developmental disabilities. The intervention coupled remote audio coaching (RAC) with a mnemonic device, 'ELSE', to guide students to make decisions about whether certain jobs would be a good fit for them. The study aimed to investigate the effectiveness of the intervention and determine whether the skills would maintain once the intervention was removed. All students who received the intervention substantially increased their ability to make job decisions. Additionally, all participants maintained the skills upon removal of the intervention, and showed signs of generalizing their skills to novel job coaches and webbased job search apps. Implications and future research are discussed.
\end{abstract}

Keywords Decision-making · Employment · Intellectual and developmental disabilities $\cdot$ Remote audio coaching $\cdot$ Mnemonic strategies

\section{"What ELSE about this job?" Teaching Job Decision-Making to College Students With Intellectual and Developmental Disabilities}

The ability to make effective choices and decisions is one of the most important competencies for students with intellectual and developmental disabilities (IDD; Wehmeyer, 2020). In particular, making career or employment decisions is a critical skill required to live a self-determined life (Boles et al., 2019). Unemployment leads to financial dependency, limited community involvement, and an inability to fulfill one's potential (Billstedt et al., 2005; Hughes, 2001). The current rate of individually

Ayse Torres

atorre58@fau.edu

1 Florida Atlantic University Boca Raton, FL, USA 
integrated paid employment for adults with IDD is less than 10\% (Wehman et al., 2018). Limited support in career preparation, and a lack of pre-employment training and work experiences are major reasons for poor employment outcomes for adults with IDD (Clark et al., 2019; Southward \& Kyzar, 2017). Adequate support helps individuals with IDD to secure meaningful, long-term competitive employment and live independently (Siperstein et al., 2014; Wehman et al., 2014).

\section{Employment and Decision-Making Skills}

A "decision" is a process involving a broad set of skills that incorporates problemsolving and choice-making to select one of several already identified options (Wehmeyer, 2007). The term "choice" refers to decisions between multiple meaningful viable options (Moore \& Friedman, 2017). Choice-making and decision-making are the central elements of self-determination and require targeted, systematic instruction and practice to learn (Burke et al., 2020; Nota et al., 2007). For example, "Do you want to work in a restaurant or not?" might not actually allow choice-making if no other options are available. Having the choice of taking what is offered or nothing at all has little instructive value, and does little to enhance the quality of an individual's life (Argan \& Krupp, 2011). To practice this skill, individuals should be exposed to option-rich environments to learn to identify, evaluate, and experience the consequences of their expressed preferences and choices (Bambara, 2004).

Historically, individuals with IDD who are quite capable of making sound choices to control their lives often remain under substitute decision-making arrangements, and have fewer opportunities to make choices and express preferences in their lives (Wehmeyer \& Abery, 2013). For employment decisions in particular, many people with disabilities are given limited choices framed by professionals or well-meaning family members who do not think the person can succeed in integrated employment (Moore \& Friedman, 2017). Supporting self-determination for individuals with IDD is key to promote community inclusion, employment, and increased quality of life (Wehmeyer, 2020). There is a causal link between self-determination and better school and adult outcomes (e.g., employment and community access) for youth with IDD (Burke et al., 2020). Career exploration interventions are excellent vehicles to help college students develop an understanding of their strengths, limitations, needs, and preferences, all of which are essential for self-determination (Wehmeyer \& Field, 2007). Interventions to teach job decision-making also have the potential to address the most common barriers for students with IDD; this includes unclear goals, unrealistic expectations, lack of vocational information, lack of self-awareness, and perceived barriers (Argan \& Krupp, 2011; Germeijs \& DeBoeck, 2003; Kaur \& Kaur, 2017; Ochs \& Roessler, 2001).

Choice-making and decision-making have been taught using methods such as task analysis (Belfiore et al., 1994; Cooper \& Browder, 1998; Lattimore et al., 2003), picture books (Faw et al., 1996), forced-choice preferences (Browder et al., 1998), computer assisted instruction (Mazotti et al., 2010), multimedia social stories (Richter \& Test, 2011), and Self-Determined Learning Model of Instruction (SDLMI; Burke et al., 2019; Shogren et al., 2019). A recent literature review showed 
that these methods are effective in teaching self-determination skills to students with disabilities however, additional intervention research is sorely needed (Raley et al., 2018).

\section{Remote Audio Coaching}

Covert audio coaching (CAC) has been used to teach various job and work-related social skills to adolescents and adults with IDD (Allen et al., 2012; Bennett et al., 2013a, 2013b; Gilson et al., 2016). CAC is a form of performance feedback that involves an instructor providing coaching statements linked to a participant's performance (Bennett et al., 2010). Remote Audio Coaching is a technology-assisted application of CAC (Joseph et al., 2021), in which coaching and instruction is delivered remotely using web-based applications (apps) such as Zoom or WebEx. RAC emerged during the COVID-19 pandemic as a modification of CAC, when educators discovered a need to implement virtual interventions. Two recent studies implemented RAC through a videoconferencing app, demonstrating that RAC was effective at increasing employment skills in college students with IDD (Kearney \& Torres, 2020, Torres et al., 2021).

\section{Mnemonic Instruction}

A mnemonic is an instructional strategy to help individuals connect new learning to prior knowledge through visual and/or acoustic cues such as key words, rhyming words, or acronyms (Scruggs et al., 2010). Mnemonic instruction has been used with students with disabilities to teach academic content (Mastropieri et al., 1985; Zisimopoulos, 2010), problem solving skills (Scruggs \& Mastropieri, 1992), completion of job applications (Nelson et al., 1994), employment soft skills (Clark et al., 2018), and to improve problem behaviors (Smith et al., 1994). In addition, several mnemonic instruction studies demonstrated positive results with students with IDD (Konrad et al., 2017; Lee et al., 2006; Mastropieri \& Scruggs, 1989; Test \& Ellis, 2005). To date two studies used mnemonic instruction related to employment skills for students with disabilities. The first study used mnemonic instruction to teach students to complete all portions of a job application (Nelson et al., 1994). The second study focused on teaching students soft skills used at job sites (Clark et al., 2018).

\section{What ELSE about this job?}

Recently, Kearney and Torres (2020) examined the impact of RAC on increasing job search skills among college students with IDD. In that study, investigators observed that when students reviewed lists of vacant jobs, they were unable to discriminate between appropriate and inappropriate jobs based on their personal circumstances. To address this gap, authors in the current study developed a multicomponent intervention to help students determine job fit. The intervention, "What ELSE about this job?", coupled RAC with a 4-step mnemonic device 'ELSE': (a) What is the 
Education level required for this job? (b) Do I Like the job responsibilities? (c) What $\boldsymbol{S}$ kills are required for this job? and (d) What are the Earnings from this job? The following research questions were addressed:

1. What are the effects of "What ELSE about this job?" on the acquisition of job decision-making skills for college students with IDD using job search websites with job coaches?

2. Will the skills learned through "What ELSE about this job?" maintain once the intervention is removed?

3. Will the decision-making skills generalize to novel job search websites and job coaches?

\section{Method}

\section{Participants}

Three students, Shirley, Lynn, and Duncan, enrolled in an inclusive postsecondary education (IPSE) program at a university in the southeastern region of the United States participated in this study. Each student had a primary diagnosis of intellectual disability (ID) based on their most recent psychological evaluation on the Wechsler Adult Intelligence Scale - Fourth Edition (WAIS-IV; Wechsler, 2008). Shirley and Lynn were both White women, 22 years old, with full scale IQ scores of 62 and 70 respectively. Duncan was a White male, 26 years old, with a full scale IQ score of 74. Duncan also was diagnosed with an Autism Spectrum Disorder.

Each student had an employability assessment on the Job Observation Behavior Scale: Opportunity for Self Determination (JOBS: OSD; Brady et al., 2006). JOBS:OSD assesses students' perception of their work performance (WP), and the degree to which they can work with varying types of support (TS). On the JOBS:OSD Work Related Daily Living subscale, Shirley scored 34, with a type of support score of 35, which is near the mean for a comparison group of entrylevel employees. On the Work Required Behavior subscale, Shirley scored 23 with a support score of 21, below but near the mean for the entry-level employees. On the Work Required Job Duty subscale, Shirley scored 23 with a support score of 21, near the mean for the entry-level employees. These scores indicate that Shirley perceived that she could perform most entry-level job tasks independently or with intermittent support. Profiles were similar for Lynn and Duncan. Lynn's WP scores and TS scores were 38 and 35 for the Daily Living subscale, 18 and 18 for the Behavior subscale, and 24 and 23 for the Job Duties subscale. For Duncan, WP scores and TS scores were 39 and 36 for the Daily Living subscale, 24 and 22 for the Behavior subscale, and 27 and 27 for the Job Duties subscale. Although Lynn self-reported lower work performance and more need for employment support than comparison groups of entry-level employees, the remainder of both students' scores were close to other employees with developmental disabilities.

Each student was enrolled in the IPSE program for more than a year and all communicated their needs independently. Lynn was assessed as having a sixth-grade 
reading level. Instructors in the IPSE program identified Shirley, Lynn, and Duncan as ideal candidates due to their lack of employment history, as well as their limited experiences in job searching. None of the students had paid job experience, although Duncan and Lynn had volunteered in community activities. Participation in the study required consistent attendance and satisfactory performance in all current classes. Students provided written and verbal assent, and their guardians provided written consent prior to participation. The study received approval from the University's institutional review board before the researchers contacted students.

\section{Setting}

All aspects of the study took place virtually. Sessions were conducted via Zoom, a widely used videoconferencing application. Researchers used a professional Zoom account to prevent potential privacy issues. Students downloaded the Zoom application to their laptops or tablets prior to the study. Each student was familiar with the application and had at least eight months of experience using it for their college coursework. Researchers and students worked from their individual home offices. Prior to the study, researchers contacted students' caregivers and asked them not to assist or participate in the sessions; there were no observed instances of any external assistance to students.

Each baseline, intervention, and follow-up session consisted of the student, interventionist, and primary data collector. A secondary data collector was present for selected sessions for interobserver agreement or fidelity purposes. For the purpose of providing generalization probes, a job coach attended some sessions. Data collectors kept their cameras and microphones off and removed their names from the screen, ensuring that participants could only see and hear the interventionist. This minimized potential distractions and lessened the probability of any undue influence data collectors might cause the students.

\section{Materials}

All students used their personal laptops, tablets, or smartphones during the study. The Career One Stop web site was used to show students the career videos, and the "What ELSE about this job?" visual (created from PowerPoint) was used to teach students the ELSE mnemonic used to determine appropriate job fit.

\section{Career One Stop}

Career One Stop (https://www.careeronestop.org/) is a website funded by the U.S. Department of Labor that allows individuals to explore careers, trainings, and local jobs. The career videos section of this website includes hundreds of different career videos providing information about jobs, with job relevant tasks, responsibilities, and skills that make up the jobs. The length of each career videos is from one to two 
minutes. There is also a section that provides information regarding average pay, typical training and/or degree requirements, and prospects for future career opportunities. Prior to the study, researchers created two pools of selected career videos: appropriate jobs and inappropriate jobs. Prior to each session, the interventionist randomly selected one video to present to students.

\section{ELSE Visual}

A visual graphic, "What ELSE about this job?" was created with four boxes, one for each letter of the ELSE mnemonic: Education, Likes, Skills and Earnings. Under each box, two questions were posed. For example, under education, the questions were: (a) What is the Education level needed for this job? (b) Do I have this Education level? The responses to each section provided a structure to help students compare information from various jobs, and to determine whether the job was a good fit. For each section, the student chose "Yes or No" to determine overall job fit. See Fig. 1 for the mnemonic visual.

\section{Independent Variable}

The independent variable was RAC, coupled with the ELSE mnemonic visual implemented remotely via Zoom. The interventionist, an investigator with a doctorate and experience in special education, shared her screen and used RAC to coach the student through the ELSE mnemonic visual. The investigator then shared a job description on her screen from the Career One Stop videos and said, "What ELSE about this job?" The student used the ELSE mnemonic to go through the job decision-making task analysis to determine if the job was a good fit. If the student made an error on any step, the interventionist would use RAC to correct the step. For example, if the participant forgot to list the skills the job required, the interventionist used her microphone to say, "S-stands for skills - what skills does someone need for this job?".

\section{WHAT ELSE ABOUT THIS JOB?}

\begin{tabular}{|c|c|c|c|c|c|c|c|}
\hline \multicolumn{2}{|c|}{ EDUCATION } & \multicolumn{2}{|c|}{ LIKE } & \multicolumn{2}{|c|}{ SKILLS } & \multicolumn{2}{|c|}{ EARNINGS } \\
\hline $\begin{array}{c}\text { JOB } \\
\text { What is the } \\
\text { education } \\
\text { level for this } \\
\text { job? }\end{array}$ & $\begin{array}{l}\text { ME } \\
\text { Do I have } \\
\text { this } \\
\text { Education } \\
\text { level? }\end{array}$ & $\begin{array}{l}\text { JOB } \\
\text { What are the } \\
\text { responsibilities } \\
\text { of this job? }\end{array}$ & \begin{tabular}{|c} 
ME \\
Do I Like these \\
responsibilities?
\end{tabular} & $\begin{array}{l}\text { JOB } \\
\text { What are the } \\
\text { skills needed } \\
\text { for this job? }\end{array}$ & $\begin{array}{l}\text { ME } \\
\text { Do I have } \\
\text { these } \\
\text { Skills? }\end{array}$ & $\begin{array}{c}\text { JOB } \\
\text { How much } \\
\text { does this } \\
\text { job pay? }\end{array}$ & $\begin{array}{c}\text { ME } \\
\text { Will I be } \\
\text { happy with } \\
\text { the Earnings? }\end{array}$ \\
\hline & & & & & & & \\
\hline & & & & & & & \\
\hline
\end{tabular}

Fig. 1 ELSE Mnemonic Visual Graphic 


\section{Dependent Variable and Data Collection}

The researchers created a task analysis of the job decision-making skill using the mnemonic ELSE. The task analysis was comprised of 12 steps, two of which could be omitted during a session based on a student's response to the particular job description being discussed. See Table 1 for the task analysis. The dependent variable was the percentage of steps completed correctly and independently in the decision-making task analysis. Each step in the task analysis was scored by a data collector as either (a) correct or (b) incorrect; if correct, then the data collector scored whether the step was completed independently.

Every session in each condition began with a 5-min data collection probe. During intervention sessions, the intervention was delivered immediately after the data collection probe. This guaranteed a minimum of $24 \mathrm{~h}$ between the implementation of the intervention and the next data collection probe, avoiding immediate practice effects and artificially inflated scores. All data were converted to percentages by dividing the number of steps correct by the total number of steps and multiplying by 100 .

One researcher served as the primary data collector during all sessions and conditions. She had a graduate degree in rehabilitation counseling and had experience working with adults with IDD. The data collector remained unseen to the students at all times, by keeping her camera off, her name removed from the screen, and her microphone muted during each observation. A second investigator served as a back-up data collector and for observer agreement and fidelity observations. The secondary observer was a doctoral student with a graduate degree in special education and had experience working with adults with IDD.

Table 1 Task Analysis of Job Decision Making Using ELSE Mnemonic

\author{
Steps for Job Decision-Making \\ 1.Identify education level \\ 2. Identify if Education level is a good fit $\mathrm{Y} / \mathrm{N}$ \\ 3. Identify what are the job responsibilities \\ 4. Identify if I Like these responsibilities Y/N \\ 5. Identify skills needed \\ 6. Identify if I have these Skills Y/N \\ 7. Identify how much does this job pay \\ 8. Identify if I am satisfied with the Earnings Y/N \\ 9. Identify how many NOs \\ 10. **Identify if a NO can change \\ 11. Identify if the job is a good fit for now \\ 12. **Identify if the job is a good fit for later
}

\footnotetext{
** Indicates this step may not be completed depending upon immediate prior answer
} 


\section{Interobserver Agreement and Treatment Fidelity}

Data were collected live and simultaneously by two observers during $46 \%$ of all sessions to determine interobserver agreement (IOA). The two observers collected agreement data during 40\%, 39\%, and 75\%, respectively, during baseline, intervention, and follow-up sessions. During all IOA sessions, a secondary data collector logged onto the Zoom link to observe the session. Like the primary data collector, the secondary observer appeared on the screen as an empty black box, with her camera and microphone off, and her name removed. Agreement was determined by counting the number of steps in the task analysis in agreement, then dividing that number by the total number of opportunities for agreement, then multiplying by 100. Agreement on Shirley's observations averaged 99\%, agreement on Lynn's observations averaged 97\%, and agreement on Duncan's observations averaged $96 \%$.

The researchers also created a checklist to establish treatment fidelity. A 4-step fidelity checklist was used during baseline and follow-up conditions to ensure that experimental procedures were followed, but no part of the intervention was delivered. A 5-step fidelity checklist was used during the intervention condition to ensure that the interventionist used the ELSE and RAC intervention accurately. A data collector gathered fidelity data for all students during $88 \%$ of all baseline, intervention, and follow-up sessions. During each fidelity observation, the interventionist implemented the experimental protocol with $100 \%$ fidelity.

\section{Experimental Design and Procedures}

A multiple probe design across participants was used to determine the impact of the intervention on students' job decision-making skills. The probe design prevents prolonged, inaccurate practice of a new skill (Kennedy, 2005). Introducing the intervention in a systematic, staggered way demonstrates that the increase in skill acquisition is due to the introduction of the intervention rather than chance.

\section{Baseline}

All baseline sessions began with the interventionist, student, and data collector logged into Zoom. The interventionist shared her screen, so everyone could see the same career video from the Career One Stop website. The interventionist then said, "Tell me what ELSE about this job". No other instruction was provided. All student behavior was observed for multiple days. The researchers introduced the intervention after at least three data points demonstrated a low and stable (or decelerating) trend of accurate skill performance. The baseline session ended if the student did not complete any of the steps in the task analysis after $15 \mathrm{~s}$, or if students verbally indicated that they did not know what to do. 


\section{Intervention}

All intervention sessions began with the interventionist, student, and data collector(s) logged into Zoom. The intervention for this study consisted of the visual ELSE mnemonic and RAC delivered by an interventionist via Zoom. Students received the intervention individually during a 10-min period. As described during the data collection section, a data collection probe was administered approximately five minutes prior to delivering the intervention to assure a 24-h gap between the intervention and a subsequent data collection probe (to avoid immediate practice effects).

Once the data collection probe was completed for that session, the intervention was administered. The interventionist shared her screen to display the visual ELSE mnemonic. The interventionist verbally practiced the visual with the student, then displayed the career video and said, "Tell me what ELSE about this job." The student then went through the task analysis using the visual mnemonic. If an error was made, the interventionist stopped the student and provided a verbal prompt based on the mnemonic. For example, if the student said how much money the job paid but did not state if he or she liked those earnings, then the interventionist would ask, "Will you be happy with those earnings?". Once a student reached mastery criteria of three consecutive sessions at $100 \%$ correct and independent, no further intervention sessions were delivered to that student, and a follow-up condition was implemented.

\section{Follow-Up}

Follow-up procedures were identical to baseline procedures. All follow-up sessions began with the interventionist, student, and data collector(s) logged into Zoom. The interventionist shared her screen to display the career video, then stated, "Tell me what ELSE about this job." She provided no other instruction after that. The followup condition was implemented once each student met mastery criteria to determine if the skill would maintain upon removal of the intervention. All students received follow-up probes on the same schedule. The first follow-up probe occurred 10 days after the removal of the intervention, and the second follow-up probe occurred 17 days after the removal of the intervention.

\section{Generalization}

The generalization sessions followed the same procedure as baseline sessions but used a different medium of communicating the job opportunity. This enabled the researchers to determine whether the students would generalize the job decisionmaking skills to a different medium. All generalization sessions began with the interventionist, student, and data collector(s) logged into Zoom. There were two types of generalization probes: (a) generalization that involved using a job listing on a novel website (e.g., indeed.com), and (b) generalization by providing information 
to a novel job coach. During the website generalization probes, no instruction was provided. The interventionist shared her screen and displayed a job listing on the website. While sharing the listing, the interventionist said, "Tell me, what ELSE about this job?". One website generalization probe was delivered during baseline, intervention, and follow-up conditions for each student.

During the job coach generalization probes, no instruction was provided. The job coach joined the Zoom link prior to the student being admitted from the waiting room. Her screen camera remained off until she was prompted to show herself by the interventionist. These generalization sessions began with the interventionist telling the student, "A job coach will be joining to talk about a potential job opportunity." She then asked the student to think and ask the coach "What ELSE about this job?" The job coach then turned on her camera and said, "Hi, I know about a job as a XYZ. Would you be interested in this job?". The job coach did not provide any further information about the job unless the student asked specific questions about it (e.g., what skills are needed for this job?). One job coach generalization probe occurred during each student's baseline conditions, two occurred during intervention conditions, and one occurred during follow-up conditions.

\section{Data Analysis}

First, data were analyzed with traditional visual inspection procedures. The researchers calculated central tendency measures and determined data ranges for each student during baseline, intervention, and follow-up. Researchers determined level, trend, and variability of the data across conditions to make decisions regarding condition changes (Kratochwill et al., 2013). After the visual inspection, researchers used percentage of nonoverlapping data (PND) as an estimate of effect size for the intervention. PND remains one of the most commonly used methods to establish effect size in single-subject design research (Scruggs \& Mastropieri, 2013). Researchers established PND for each student's baseline to intervention differences, as well as baseline to follow-up differences, and used Scruggs and Mastropieri's standards to interpret results. The intervention was determined to be (a) very effective if 90-100\% of intervention data do not overlap with baseline, (b) moderately effective if 70-90\% of intervention data do not overlap, (c) minimally effective if $50-70 \%$ of intervention data do not overlap, and (d) not effective if $50 \%$ or more of intervention data overlap.

\section{Social Validity}

Perceptions of students and professionals in the field were assessed to evaluate the social validity of the ELSE mnemonic and the remote delivery of the intervention. Students who participated in the study and four job coaches who work for a community-based vocational rehabilitation provider were asked to complete a post-study questionnaire. The questionnaire was emailed to all participants approximately one week after the last observational data were collected. 
The social validity questionnaire for the students contained three questions and used a Likert-type scale with added visuals to signify four possible responses: Absolutely (4.0), Kind of, Not Really, and No Way (1.0). Each item represented one of the three social validity components described in the seminal work by Wolf (1978): the significance of the goal, the effectiveness of the intervention, and satisfaction with the intervention and impact. A different questionnaire was developed for job coaches containing seven questions, also representing the three fundamental social validity constructs described by Wolf. The job coach questionnaire also used a Likert-type scale with four available responses; Strongly Agree (4.0), Agree, Disagree, and Strongly Disagree (1.0), along with an unscored response for Not Sure. Data were analyzed by calculating means for each item, and for the job coaches, calculating the aggregate of the items for each of the three social validity categories.

\section{Results}

A summary of performance within and across conditions for each student is found in Table 2. The percentage of correct and independent performance is displayed in Fig. 2.

\section{Shirley}

During Shirley's first baseline session she completed $8 \%$ of the steps in the task analysis correctly and independently. Her second session increased to $25 \%$ correct and independent. She performed $17 \%$ of the steps correctly and independently during both the website generalization probe and the job coach generalization probe. Shirley's intervention was implemented after the third session. She demonstrated an immediate increase in job decision-making skills after the first intervention session, performing $42 \%$ of the steps correctly and independently. In her first generalization session with the job coach, she performed $17 \%$ of the steps correctly, which was significantly lower than she was performing in the intervention session immediately prior and after this generalization session. On her website generalization probe on session 16 , Shirley performed $100 \%$ of the steps correctly and independently. During her second job coach generalization session she performed $83 \%$ of the steps correctly and independently. She had a steady, accelerating trend in skill acquisition and required 13 intervention sessions before reaching mastery criteria on session 20 . Her follow-up data showed slight variability. On her first follow-up session, which occurred 10 days after the intervention was removed, Shirley scored $83 \%$ correct and independent. On her second follow-up session, 17 days after the intervention was removed, she completed $100 \%$ of the steps in the task analysis correctly and independently, and scored $100 \%$ on both generalization probes in follow-up. 
Table 2 Student Performance Within and Across Conditions

\begin{tabular}{|c|c|c|c|}
\hline Participant & Baseline & Intervention & Follow-up \\
\hline Shirley & 5 sessions & 16 sessions & 4 sessions \\
\hline Observation sessions & $17 \%$ & $75 \%$ & $100 \%$ \\
\hline Intervention data: Median & $17 \%$ & $71 \%$ & $96 \%$ \\
\hline Intervention data: Mean & $(8 \%-25 \%)$ & $(42 \%-100 \%)$ & $(83 \%-100 \%)$ \\
\hline Intervention data: Range & Stable & Ascending & Ascending \\
\hline Trend direction & $17 \%$ & $100 \%$ & $100 \%$ \\
\hline Website generalization & $17 \%$ & $17-83 \%$ & $100 \%$ \\
\hline $\begin{array}{l}\text { Job coach generalization } \\
\text { PND }\end{array}$ & N/A & $100 \%$ & $100 \%$ \\
\hline Lynn & 7 sessions & 14 sessions & 4 sessions \\
\hline Observation sessions & $8 \%$ & $67 \%$ & $88 \%$ \\
\hline Intervention data: Median & $11 \%$ & $61 \%$ & $86 \%$ \\
\hline Intervention data: Mean & $(8 \%-17 \%)$ & $(17 \%-100 \%)$ & $(92 \%-100 \%)$ \\
\hline Intervention data: Range & Stable & Ascending & Ascending \\
\hline Trend direction & $8 \%$ & $75 \%$ & $83 \%$ \\
\hline Website generalization & $8 \%$ & $8 \%-67 \%$ & $67 \%$ \\
\hline $\begin{array}{l}\text { Job coach generalization } \\
\text { PND }\end{array}$ & N/A & $91 \%$ & $100 \%$ \\
\hline Duncan & 8 sessions & 10 sessions & 4 sessions \\
\hline Observation sessions & $17 \%$ & $83 \%$ & $100 \%$ \\
\hline Intervention data: Median & $15 \%$ & $78 \%$ & $100 \%$ \\
\hline Intervention data: Mean & $(8 \%-17 \%)$ & $(25 \%-100 \%)$ & Stable \\
\hline Intervention data: Range & Stable & Ascending & $100 \%$ \\
\hline Trend direction & $17 \%$ & $83 \%$ & $100 \%$ \\
\hline Website generalization & $17 \%$ & $50-75 \%$ & $100 \%$ \\
\hline $\begin{array}{l}\text { Job coach generalization } \\
\text { PND }\end{array}$ & N/A & $100 \%$ & \\
\hline
\end{tabular}

Percentage of Non-overlapping Data (PND) calculated between Baseline and Intervention, and between Baseline and Follow-up for the intervention data only

\section{Lynn}

During Lynn's first two baseline sessions she completed $8 \%$ of the steps in the task analysis correctly and independently. She performed $8 \%$ of the steps correctly and independently during both the website and the job coach generalization probes. The third and fourth baseline sessions increased to $17 \%$, but by the fifth baseline session the skill decreased to $8 \%$ correct and independent. The intervention was implemented after this session. Lynn demonstrated an immediate increase in decision-making skills after the first intervention session, performing $25 \%$ of the steps correctly and independently, however her second session decreased to $17 \%$. By her fifth session she began a strong, steady accelerating trend in skill acquisition. In her first generalization probe with the job coach, Lynn performed $8 \%$ of the steps, which was significantly lower than the intervention session immediately prior to and after this generalization session. On her website generalization probe Lynn performed $75 \%$ of the steps. During her second job coach generalization probe, Lynn performed $67 \%$ of the steps correctly and independently. She had a steady, accelerating trend in acquisition 


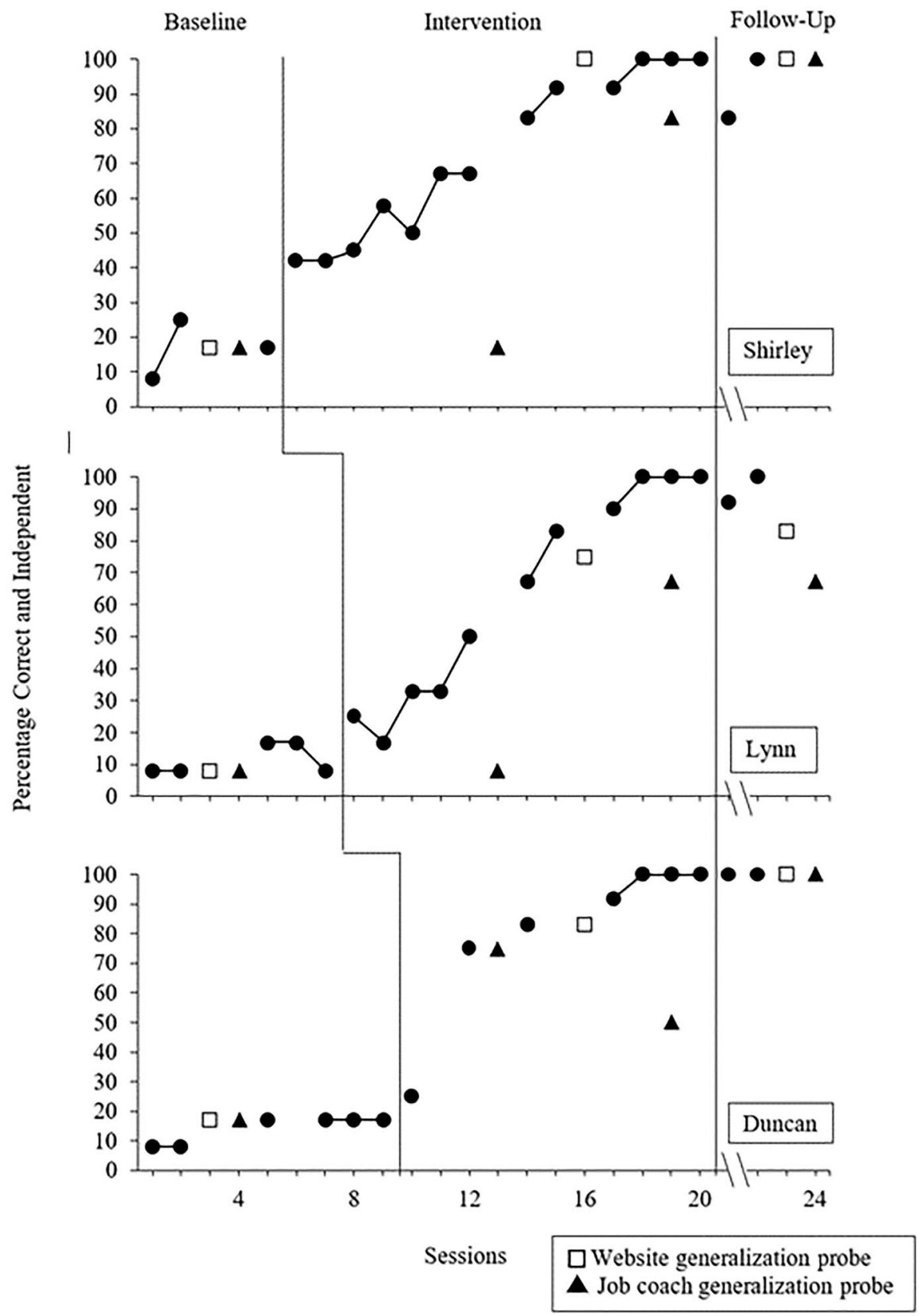

Fig. 2 Percentage of Correct and Independent Responses

and required 11 intervention sessions before reaching mastery criteria on session 20 . Her follow-up data were slightly variable. On her first follow-up session 10 days after the intervention was removed, Lynn scored $92 \%$. On her second follow-up session, 
17 days after the intervention was removed, she scored $100 \%$ correct and independent. During follow-up generalization probes, Lynn scored $83 \%$ on the website generalization probe, and $67 \%$ with the job coach generalization probe.

\section{Duncan}

During the first two baseline sessions Duncan completed 8\% of the steps in the task analysis correctly and independently. He performed $17 \%$ of the steps during both the website and job coach generalization probes. His third session increased to $17 \%$, and he continued to perform at this level until session 9. After this session, Duncan's intervention was implemented. Duncan's first intervention increased slightly, with $25 \%$ of the steps correct and independent. He then began a strong accelerating trend, increasing to $75 \%$. In his first generalization session with the job coach, Duncan performed $75 \%$ of the steps. On his website generalization probe on session 16, he performed $83 \%$ of the steps. During his second job coach generalization session Duncan's performance decreased to 50\%. Overall, he had a steady, accelerating trend in his skill acquisition and required seven intervention sessions before reaching mastery criteria on session 20. Afterward, his follow-up data remained strong and stable. On his first follow-up session, Duncan scored $100 \%$. On his second follow-up session, he scored 100\% correct and independent, and scored $100 \%$ on both generalization probes.

\section{Post Hoc Analysis and Effect Size}

A post-hoc analysis of the results using the percentage of non-overlapping data indicated that the instructional package was very effective based on standards by Scruggs and Mastropieri (2013). The PND between baseline and intervention for Shirley and Duncan was $100 \%$. The PND between baseline and intervention for Lynn was $91 \%$. The PND between baseline and follow-up for all students was $100 \%$. Overall, visual inspection of graphed data and PND indicates that the intervention was highly effective.

\section{Social Validity Results}

Across all items and respondents, there was strong evidence of social validity for the ELSE mnemonic and RAC intervention to teach job decision-making skills. The response rate for both the students and job coaches returning the questionnaire was $100 \%$. Students provided high ratings for the significance of the goal (3.67 of 4.0), effectiveness of the intervention (3.5), and their satisfaction with the impact and the intervention (4.0). Job coaches provided strong and unanimous social validity ratings for the items that formed all three social validity categories [significance of the goal (4.0), effectiveness of the intervention (4.0), and their satisfaction with the 
impact and the intervention (4.0)]. Individual ratings for the three social validity categories for the students and job coaches are summarized in Table 3.

\section{Discussion}

The purpose of this study was to determine the impact of "What ELSE about this job?" on job decision-making skills of college students with IDD. Additionally, the researchers sought to determine whether the students would continue to use the decisionmaking skills once the intervention was removed. All students who received the intervention substantially increased their appropriate job decision-making skills, and the effect sizes indicated that the intervention was highly effective for all students.

Students in this study did not immediately generalize their skills across novel job search websites. Students reported that job details on the generalization job search websites were located in unique parts of the sites, making it difficult for them to find the needed information. It could be that the generalization difficulties with the websites was simply due to a need for more time to become familiar with these sites, a scenario that would enable students to develop further this skill set.

The generalization probes conducted with a job coach were more challenging than generalization probes across novel job websites for all the students. When interacting with the job coach during the generalization probes, all students showed a tendency to respond immediately as soon as they heard the job coach say the title of the job rather than working through the ELSE mnemonic. It seemed that students did not see the need to question the job coach about the employment recommendation. Perhaps students believed that the job coach would not approach them with an inappropriate job, so they were less likely to use the decision-making skills they

Table 3 Social Validity Outcomes

\begin{tabular}{llll}
\hline Participants & Significance of Goal & $\begin{array}{l}\text { Effectiveness of } \\
\text { Intervention }\end{array}$ & Satisfaction \\
& Students (3 Items; *Rating=1-4) & & \\
\hline Shirley & 4.0 & 4.0 & 4.0 \\
Lynn & 3.0 & 3.5 & 4.0 \\
Duncan & 4.0 & 3.0 & 4.0 \\
Total & 3.67 & 3.5 & 4.0 \\
& Professionals (7 Items; **Rating =1-4 with NA option) & \\
Job Coach 1 & 4.0 & 4.0 & 4.0 \\
Job Coach 2 & 4.0 & 4.0 & 4.0 \\
Job Coach 3 & 4.0 & 4.0 & 4.0 \\
Job Coach 4 & 4.0 & 4.0 & 4.0 \\
Total & 4.0 & 4.0 & 4.0 \\
\hline
\end{tabular}

*Student Ratings: 4=Absolutely, 3=Kind of, $2=$ Not really, $1=$ No Way. **Professional Ratings: $4=$ Strongly Agree, $3=$ Agree, $2=$ Disagree, $1=$ Strongly Disagree 
were learning outside of the generalization session. This finding will be pursued in our future studies.

This study extends the self-determination literature by using a mnemonic device coupled with RAC. This intervention is the first to incorporate a remote instructional method for teaching job decision-making skills to college students with IDD. There are several advantages to using "What ELSE about this job?". First, the ability to offer this novel intervention virtually increases the accessibility of job decisionmaking skills training for all students with disabilities, especially students with limited accessibility. Second, this intervention can be implemented by educators, vocational rehabilitation practitioners, and family members with minimal training. Third, this intervention gives teachers the opportunity to expand their traditional or virtual instruction by providing an additional tool to teach core self-determination skills. Finally, this intervention can be delivered face-to-face and in small groups.

Skills associated with self-determination are critical for all students, a finding supported by the literature in numerous disciplines, including special and general education, rehabilitation, health care, and other human services. It is often assumed that students learn skills associated with self-determined action (such as problem solving and decision-making) incidentally; however, more explicit instruction needs to be dedicated to these skills (Burke et al., 2020; Shogren et al., 2016). "What ELSE about the job?" is a promising intervention to guide students with IDD. A compelling number of studies suggest that self-determination interventions can be useful when transitioning from high school to adult life. "What ELSE about this job?" can be integrated into transition curricula to help students explore their strengths, limitations, needs and preferences, increasing self-awareness and job-awareness, all goals of a college curriculum.

\section{Limitations and Recommendations for Future Research}

Like all studies, there were some limitations. First, our study only included adults with IDD in the same IPSE program. Students had similar educational backgrounds and experiences. Since most adults with IDD do not have access to inclusive college programs, students in this study do not represent the general population of adults with IDD. Second, the interventionist is an instructor in the IPSE program that all students attended, and all were familiar with her. This had the potential of making the intervention more effective. Third, the study involves technology and internet connections. During some sessions, the communication was interrupted by poor connectivity and students were asked to repeat their responses. The repetition may cause fatigue for some students, and lack of reliable Internet access may pose a barrier for students who might otherwise benefit from the intervention package. Fourth, we did not verify the fitness of the selected job in actual job environment. Finally, all students were familiar with the video-based conferencing application Zoom that was used to deliver the intervention. It is possible future students who are less familiar with Zoom might have more difficulty learning the skill.

The results of this study are encouraging and demonstrate the effectiveness of "What ELSE about this job?" on job decision-making skills for college students 
with IDD. However, replication of this study is necessary with other populations (e.g., different disabilities, age groups, and educational backgrounds). Additionally, future research can determine the generalizability of this intervention to other video-based conferencing applications such as FaceTime, Google Meet, or WebEx. Given the recent importance of remote learning, researchers need to study the impact of remote coaching and instruction for other interventions to teach decision-making and choice-making skills. Finally, additional research can compare the impact of remote instruction of "What ELSE about this job?" to face-to-face implementation. It would be useful to identify whether any difference might be discovered in the effectiveness of the intervention.

\section{Declarations}

Conflict of Interest The authors have no conflicts of interest to declare that are relevant to the content of this article.

Ethical Approval The questionnaire and methodology for this study was approved by the Florida Atlantic University Institutional Review Board (FAU-IRB; Approval number: 1646369-1).

Informed Consent Written informed consent was obtained from legal guardians of all individual participants included in the study.

\section{References}

Agran, M., \& Krupp, M. (2011). Providing choice making in employment programs: The beginning or end of self-determination? Education and Training in Autism and Developmental Disabilities, 46(4), 565-575.

Allen, K. D., Burke, R. V., Howard, M. R., Wallace, D. P., \& Bowen, S. L. (2012). Use of audio cuing to expand employment opportunities for adolescents with autism spectrum disorders and intellectual disabilities. Journal of Autism and Developmental Disorders, 42(11), 2410-2419. https:// doi.org/10.1007/s10803-012-1519-7

Bambara, L. M. (2004). Fostering choice-making skills: We've come a long way but still have a long way to go. Research and Practice for Persons with Severe Disabilities, 29(3), 169-171. https:// doi.org/10.2511/rpsd.29.3.169

Belfiore, P. J., Browder, D. M., \& Mace, C. (1994). Assessing choice-making and preference in adults with profound mental retardation across community and center-based settings. Journal of Behavioral Education, 4(2), 217-225.

Bennett, K. D., Ramasamy, R., \& Honsberger, T. (2013a). Further examination of covert audio coaching on improving employment skills among secondary students with autism. Journal of Behavioral Education, 22(2), 103-119. https://doi.org/10.1007/s10864-013-9168-2

Bennett, K. D., Ramasamy, R., \& Honsberger, T. (2013b). The effects of covert audio coaching on teaching clerical skills to adolescents with autism spectrum disorder. Journal of Autism and Developmental Disorders, 43(3), 585-593. https://doi.org/10.1007/s10803-012-1597-6

Bennett, K., Brady, M. P., Scott, J., Dukes, C., \& Frain, M. (2010). The effects of covert audio coaching on the job performance of supported employees. Focus on Autism and Other Developmental Disabilities, 25(3), 173-185. https://doi.org/10.1177/1088357610371636

Billstedt, E., Gillberg, C., \& Gillberg, C. (2005). Autism after adolescence: Population-based 13-to 22-year follow-up study of 120 individuals with autism diagnosed in childhood. 
Journal of Autism and Developmental Disorders, 35(3), 351-360. https://doi.org/10.1007/ s10803-005-3302-5

Boles, M., Ganz, J., Hagan-Burke, S., Hong, E. R., Neely, L. C., Davis, J. L., \& Zhang, D. (2019). Effective interventions in teaching employment skills to individuals with developmental disabilities: A single-case meta-analysis. Review Journal of Autism and Developmental Disorders, 6, 200-215. https://doi.org/10.1007/s40489-019-00163-0

Brady, M.P., Rosenberg, H., \& Frain, M. (2006). Job Observation and Behavior Scale: Opportunity for Self Determination (JOBS: OSD). [Examiner's manual]. Stoelting.

Browder, D. M., Cooper, K. J., \& Lim, L. (1998). Teaching adults with severe disabilities to express their choice of settings for leisure activities. Education and Training in Mental Retardation and Developmental Disabilities, 33(3), 228-238.

Burke, K. M., Raley, S. K., Shogren, K. A., Hagiwara, M., Mumbardó-Adam, C., Uyanik, H., \& Behrens, S. (2020). A meta-analysis of interventions to promote self-determination for students with disabilities. Remedial and Special Education, 41(3), 176-188. https://doi.org/10.1177/0741932518802274

Burke, K. M., Shogren, K. A., Antosh, A. A., Raley, S. K., LaPlante, T., \& Wehmeyer, M. L. (2019). Implementing evidence-based practices to promote self-determination: Lessons learned from a state-wide implementation of the self-determined learning model of instruction. Education and Training in Autism and Developmental Disabilities, 54(1), 18-29.

Clark, K. A., Test, D. W., \& Konrad, M. (2018). UPGRADE your performance: Improving soft skills of students with disabilities. Journal of Vocational Rehabilitation, 49(3), 351-365. https://doi.org/10. 3233/JVR-180979

Clark, K. A., Test, D. W., \& Konrad, M. (2019). Teaching soft skills to students with disabilities with UPGRADE your performance. Education \& Training in Autism \& Developmental Disabilities, 54(1), 41-56.

Cooper, K. J., \& Browder, D. M. (1998). Enhancing choice and participation for adults with severe disabilities in community based instruction. Journal of the Association for Persons with Severe Handicaps, 23(3), 252-260. https://doi.org/10.2511/rpsd.23.3.252

Faw, G. D., Davis, P. K., \& Peck, C. (1996). Increasing self-determination: Teaching people with mental retardation to evaluate residential options. Journal of Applied Behavior Analysis, 29(2), 173-188. https://doi.org/10.1901/jaba.1996.29-173

Germeijs, V., \& DeBoeck, P. (2003). Career indecision: Three factors from decision theory. Journal of Vocational Behaviour, 62(1), 11-25. https://doi.org/10.1016/S0001-8791(02)00055-6

Gilson, C. B., \& Carter, E. W. (2016). Promoting social interactions and job independence for college students with autism or intellectual disability: A pilot study. Journal of Autism and Developmental Disorders, 46, 3583-3596. https://doi.org/10.1007/s10803-016-2894-2

Hughes, C. (2001). Transition to adulthood: Supporting young adults to access social, employment, and civic pursuits. Mental Retardation and Developmental Disabilities Research Reviews, 7(2), 84-90. https://doi.org/10.1002/mrdd.1012

Joseph, B., Kearney, K. B., Brady, M. P., Downey, A., \& Torres, A. (2021). Teaching Small Talk: Increasing On-Topic Conversational Exchanges in College Students with Intellectual and Developmental Disabilities Using Remote Audio Coaching. Behavior Modification, 45(2), 251-271. https://doi.org/ $10.1177 / 0145445520975174$

Kaur, S., \& Kaur, K. (2017). Career decision making and career choice anxiety in students with learning disabilities. International Research Journal of Commerce, Arts and Science, 8(4), 133-142. https:// doi.org/10.32804/CASIRJ

Kearney, K., \& Torres, A. (2020). Using Remote Audio Coaching to Teach Job Searching to College Students with Intellectual and Developmental Disabilities. Education and Training in Autism and Developmental Disabilities.

Kennedy, C. (2005). Single-case designs for educational research. Allyn and Bacon.

Konrad, M., Clark, K. A., \& Test, D. W. (2017). Effects of GO 4 IT... NOW! Strategy instruction on expository writing skills for students with disabilities. Career Development and Transition for Exceptional Individuals, 40(1), 45-55. https://doi.org/10.1177/2165143416680884

Kratochwill, T. R., Hitchcock, J., Horner, R. H., Levin, J. R., Odom, S. L., Rindskopf, D. M., \& Shadish, W. R. (2013). Single-case intervention research design standards. Remedial and Special Education, 34(1), 26-38. https://doi.org/10.1177/0741932512452794

Lattimore, L. P., Parsons, M. B., \& Reid, D. H. (2003). Assessing preferred work among adults with autism beginning supported jobs: Identification of constant and alternating task preferences. Behavioral Interventions, 18(3), 161-177. https://doi.org/10.1002/bin.138 
Lee, S. H., Amos, B. A., Gragoudas, S., Lee, Y., Shogren, K. A., Theoharis, R., \& Wehmeyer, M. L. (2006). Curriculum augmentation and adaptation strategies to promote access to the general curriculum for students with intellectual and developmental disabilities. Education and Training in Developmental Disabilities, 41(3), 199-212.

Mastropieri, M. A., \& Scruggs, T. E. (1989). Mnemonic social studies instruction: Classroom applications. Remedial and Special Education, 10, 40-46.

Mastropieri, M. A., Scruggs, T. F., Levin, J. R., Gaffney, J., \& McLoone, B. B. (1985). Mnemonic vocabulary instruction for learning disabled students. Learning Disability Quarterly, 8(1), 57-63. https:// doi.org/10.2307/1510908

Mazzotti, V. L., Test, D. W., Wood, C. L., \& Richter, S. (2010). Effects of computer-assisted instruction on students' knowledge of postschool options. Career Development for Exceptional Individuals, $33(1), 25-40$.

Moore, R., \& Friedman, M. (2017). The role of informed choice in advancing competitive integrated employment. Journal of Vocational Rehabilitation, 46(2), 245-264. https://doi.org/10.3233/ JVR-160860

Nelson, J. R., Smith, D. J., \& Dodd, J. M. (1994). The effects of learning strategy instruction on the completion of job applications by students with learning disabilities. Journal of Learning Disabilities, 27(2), 104-110, 122. https://doi.org/10.1177/002221949402700205

Nota, L., Ferrari, L., Soresi, S., \& Wehmeyer, M. (2007). Self-determination, social abilities, and the quality of life of people with intellectual disability. Journal of Intellectual Disability Research, 51(11), 850-865. https://doi.org/10.1111/j.1365-2788.2006.00939.x

Ochs, L. A., \& Roessler, R. T. (2001). Students with disabilities: How ready are they for the 21st century? Rehabilitation Counselling Bulletin, 44(3), 170-176. https://doi.org/10.1177/003435520104400307

Raley, S. K., Shogren, K. A., Mumbardó-Adam, C., Simó-Pinatella, D., \& Gine, C. (2018). Curricula to teach skills associated with self-determination: A review of existing research. Education and Training in Autism and Developmental Disabilities, 53(4), 353-362.

Richter, S., \& Test, D. (2011). Effects of multimedia social stories on knowledge of adult outcomes and opportunities among transition-aged youth with significant cognitive disabilities. Education and Training in Autism and Developmental Disabilities, 46(3), 410-424.

Scruggs, T. E., \& Mastropieri, M. A. (2013). PND at 25: Past present, and future trends in summarizing single-subject research. Remedial and Special Education, 34, 9-19.

Scruggs, T. E., \& Mastropieri, M. A. (1992). Classroom applications to mnemonic instruction: Acquisition, maintenance, and generalization. Exceptional Children, 58(3), 219-229.

Scruggs, T. E., Mastropieri, M. A., Berkeley, S. L., \& Marshak, L. (2010). Mnemonic strategies: Evidence-based practice and practice-based evidence. Intervention in School and Clinic, 46(2), 79-86. https://doi.org/10.1177/1053451210374985

Shogren, K. A., Burke, K. M., Antosh, A. A., Wehmeyer, M. L., LaPlante, T., Shaw, L. A., \& Raley, S. K. (2019). Impact of the self-determined learning model of instruction on self-determination and goal attainment in adolescents with intellectual disability. Journal of Disability Policy Studies, 31(1), 22-34. https://doi.org/10.1177/1044207318792178

Shogren, K. A., Wehmeyer, M. L., \& Lane, K. L. (2016). Embedding interventions to promote selfdetermination within multitiered systems of supports. Exceptionality, 24(4), 213-224. https://doi. org/10.1080/09362835.2015.1064421

Siperstein, G. N., Heyman, M., \& Stokes, J. E. (2014). Pathways to employment: A national survey of adults with intellectual disabilities. Journal of Vocational Rehabilitation, 41(3), 165-178. https:// doi.org/10.3233/JVR-140711

Smith, S. W., Sigel, E. M., O’Connor, A. M., \& Thomas, S. B. (1994). Effects of cognitive-behavior training on angry behavior and aggression of three elementary-aged students. Behavioral Disorders, 19(2), 126-135. https://doi.org/10.1177/019874299401900208

Southward, J., \& Kyzar, K. (2017). Predictors of competitive employment for students with intellectual and/or developmental disabilities. Education and Training in Autism and Developmental Disabilities, 52(1), 26-37. https://doi.org/10.2307/26420373

Test, D. W., \& Ellis, M. F. (2005). The effects of LAP fractions on addition and subtraction of fractions with students with mild disabilities. Education and Treatment of Children, 28(1), 11-24.

Torres, A., Kearney, K. B., Brady, M. P., Wood, J., \& Katz, J. (2021). Using a literacy based behavior intervention to teach job interviewing skills to adults with intellectual disability. Journal of Vocational Rehabilitation, 54, 161-174. https://doi.org/10.3233/JVR-201127 
Wechsler, D. A. (2008). Wechsler Adult Intelligence Scale (4th ed.). Psychological Corporation. https:// doi.org/10.1177/1540796918810234

Wehman, P., Chan, F., Ditchman, N., \& Kang, H. (2014). Effect of supported employment on vocational rehabilitation outcomes of transition-age youth with intellectual and developmental disabilities: A case control study. Intellectual and Developmental Disabilities, 52(4), 296-310. https://doi.org/10. 1352/1934-9556-52.4.296

Wehman, P., Taylor, J., Brooke, V., Avellone, L., Whittenburg, H., Ham, W., Brooke, A. M., \& Carr, S. (2018). Toward competitive employment for persons with intellectual and developmental disabilities: What progress have we made and where do we need to go? Research \& Practice for Persons with Severe Disabilities, 43(3), 131-144. https://doi.org/10.1177/1540796918777730

Wehmeyer, M. L. (2020). Self-determination in adolescents and adults with intellectual and developmental disabilities. Current Opinion in Psychiatry, 33(2), 81-85. https://doi.org/10.1097/YCO. 0000000000000576

Wehmeyer, M. L., \& Abery, B. H. (2013). Self-determination and choice. Intellectual and Developmental Disabilities, 51(5), 399-411. https://doi.org/10.1352/1934-9556-51.5.399

Wehmeyer, M. L., \& Field, S. L. (2007). Self-determination: Instructional and assessment strategies. Corwin Press.

Wolf, M. M. (1978). Social validity: The case for subjective measurement or how applied behavior analysis is finding its heart. Journal of Applied Behavior Analysis, 11(2), 203-214.

Zisimopoulos, D. A. (2010). Enhancing multiplication performance in students with moderate intellectual disabilities using pegword mnemonics paired with a picture fading technique. Journal of Behavioral Education, 19(2), 117-133. https://doi.org/10.1007/s10864-010-9104-7

Publisher's Note Springer Nature remains neutral with regard to jurisdictional claims in published maps and institutional affiliations. 